مجلة كلية الآداب، جامعة سوهاج، العدد الثاني والخمسون، الجزء الثاني، يوليو 9 1 • بم

مدارسر النجاة الفاصة بالكوبت ودورها في تصصيح الفطاب 1الإسلامير

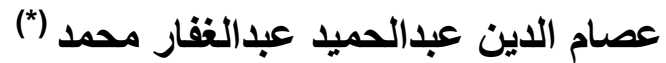

\title{
المقدمة
}

الحمد الله رب العالمين ، وأشهر ألا إله إلا الله وحده لا شريك له ، وأشهر أن أن أنها

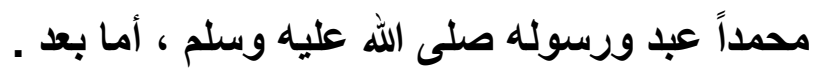
إن التعليم الخاص صنو التعليم الحكومي ، تحتاج الأمة إلى جميع مؤسساتها ولها

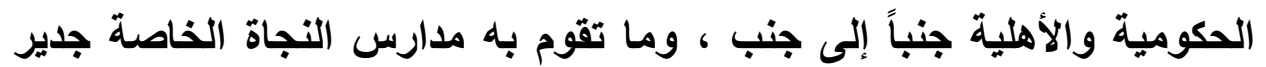

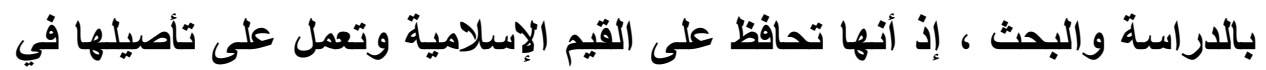
نفوس النشع الصغير ، وتربي على العقول والقلوب على التربية الإسلامية ،

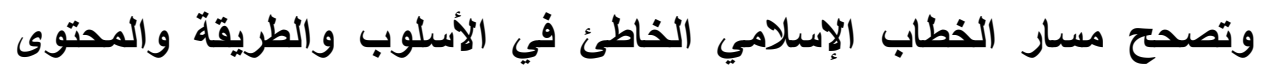

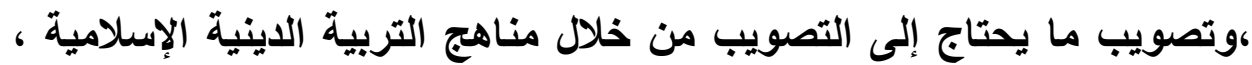

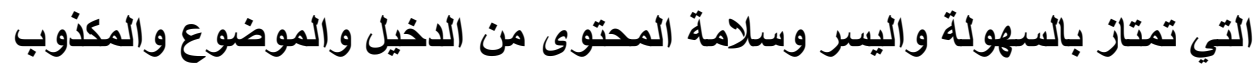

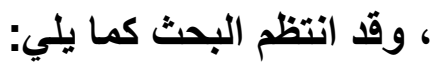

\section{فطة البهن}

المقدمـة

تمهيد

المبحث الأول : مدارس النجاة نشأتها وتاريخها وتأسيسها.

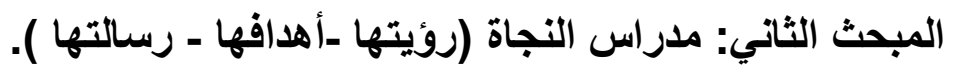

الخاتمــة

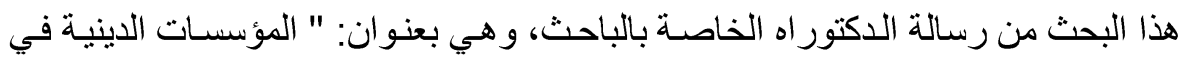

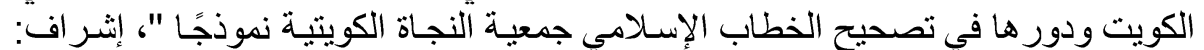

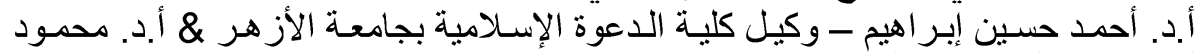
أحمد محمد أبو قمر - أستاذ التاريخ بكلية الآداب - جامعة الزقازيق.

$$
1 \cdot \mu
$$


أهمية الموضو ألمو

ا. تمثل مدارس النجاة بالكويت أيقونة التعليم الخاص بالكويت ، لريادتها

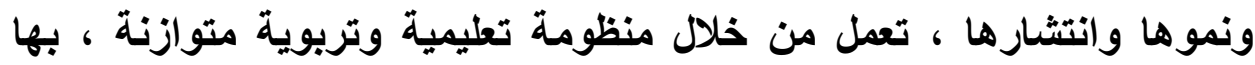
أفضل الكوادر العاملة والمدربة ، والتي تعمل على النجاة على تأهيلها وتدريبها على كل ما هو جديد ومفيا .

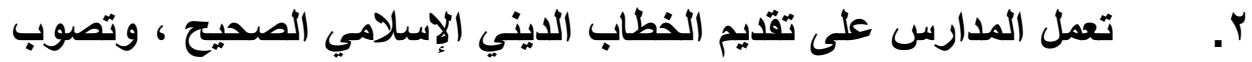

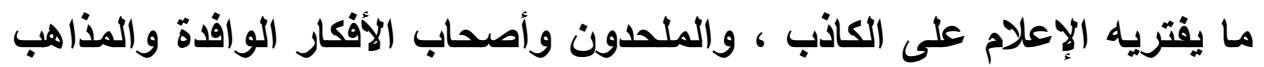

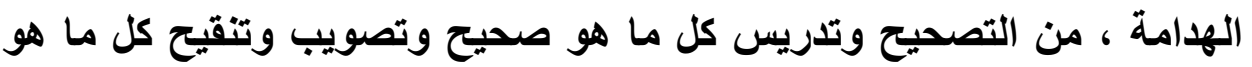

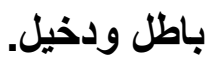

\section{التصصبم والتجدبي}

التصحيح : هو تصويب الأخطاء في الوسائل والأساليب والمحتوى والفكر ،

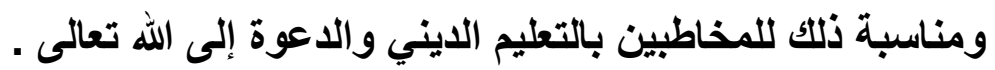

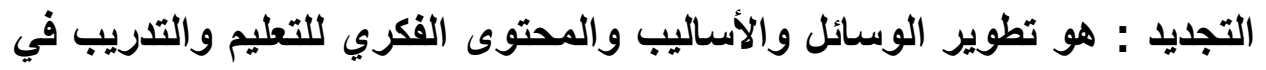

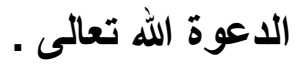

\section{موضو ع التجديد والتصصيم}

1- إن التجديا والتصحيح لا يمس مصدر الخطاب الإسلامي ( الكتاب

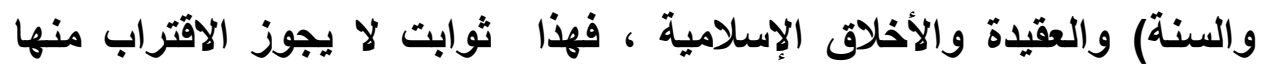
بالتغييز والتحريف والتبديل.

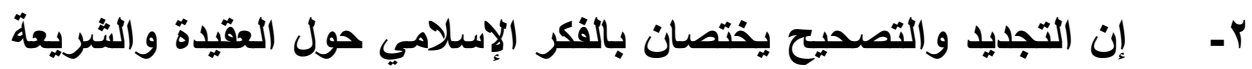

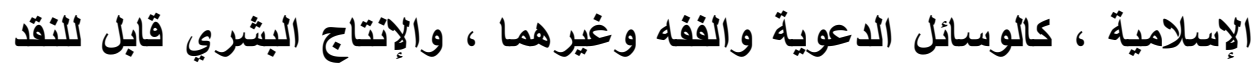
بذاته.

r- إن التجديا والتصحيح للخطاب والإسلامي لا يكون من أبناء الأمة وعلمائها الثقات ، فلا يجوز أن يفرض التجديد من أعداء الأمة ومخالقيها ، فلكل 


\section{المبـمث الأول : مدار سر النجاة نشأنها وتاريبذها وتأسبيسما.}

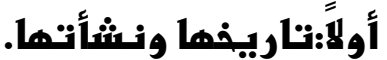

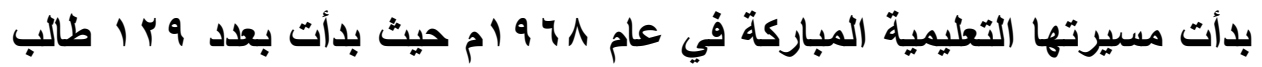

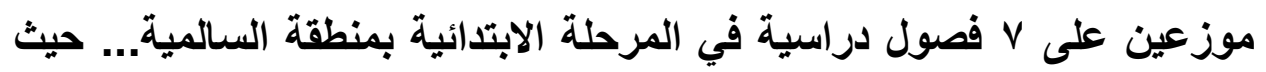

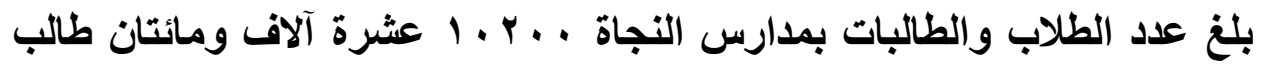

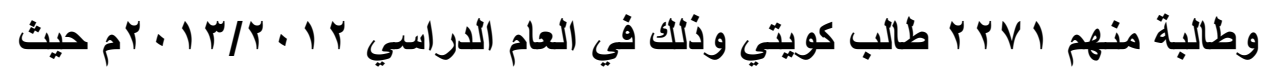
يوزع طلاب مدارس النجاة على 10 مرحلة دراسية في خمس مجمعات

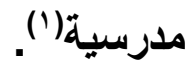

وبهذا بدأت مدارس التجاة بفصول دراسية بسيطة تطورت بالعمل الجاد والنجاح

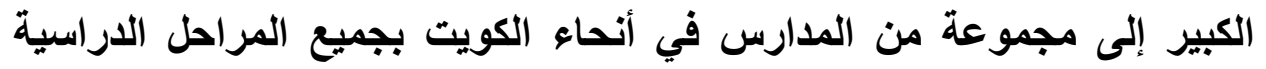
للأكور والبنات ، بها نخبة طيبة من المدرسين والتربويين يقومون على العملية

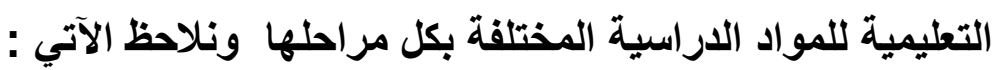

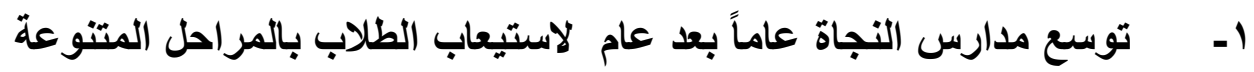
بمدارسـها.

r- إن مدارس النجاة تلتزم السلوك الإسـلامي في التعامل مع الطلاب

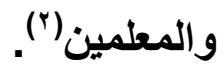
r- إن مدراس النجاة تلتزم بمناهج وزارة التربية الكويتية في العملية

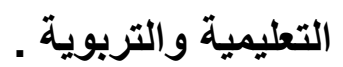

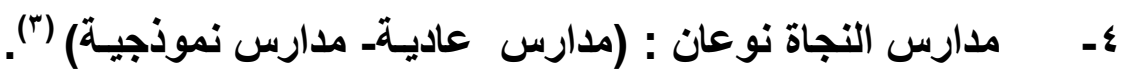
المأمول بمدارس التجاة : إضافة مدارس ثنائية اللغة لتواكب التب المدارس المدارس الأجنبية

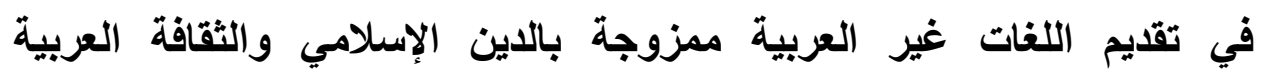
والحضارة الإنسانية ، لتسهم بالخطاب الإسلامي.

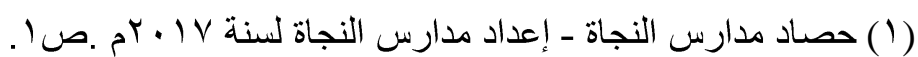

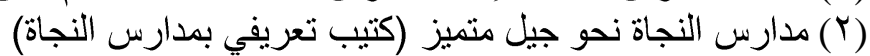

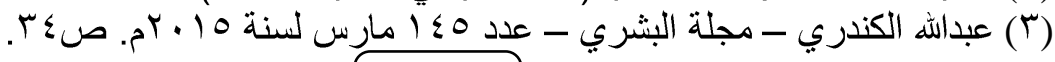
1.0 


\section{نُانباً : قصة نأسبيسر مدارسر النجاة .}

في عام 1 ه ام اجتمع مجموعة من رجالات العمل الخيري والمربين الأفاضل في بالكويت، وتعاهدوا على تأسيس مدارس عربية بهدف بناء بنه جيل متميز يحمل القرآن الكريم والأخلاق الحسنة .... وأطلقوا عليها اسم مدارس النجاة، وتكوَّن المجلس تأسيسي من أصحاب الفكرة والمؤسسين وهم : ( يوسف الحجي -أحمد المدان

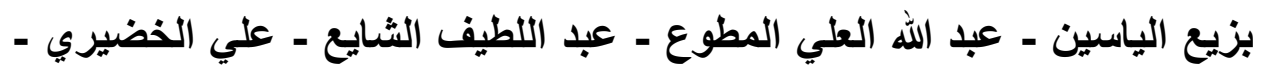

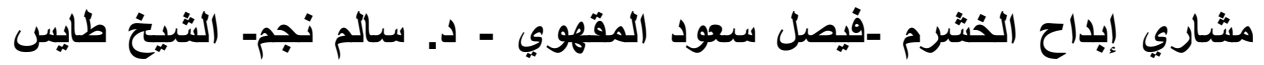
الجميلي - الثيخ حسن أيوب - عبد الله العقيل - مصطفي الطحان - عبد المنعم مشهور) (') كاتت التأسيس فكرة لثلة طيبة فكروا ونظموا ، وبدأوا بخطوات جادة عن خبرة

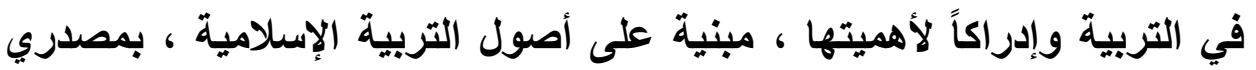

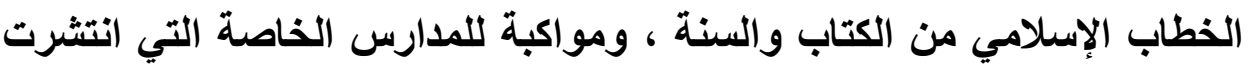

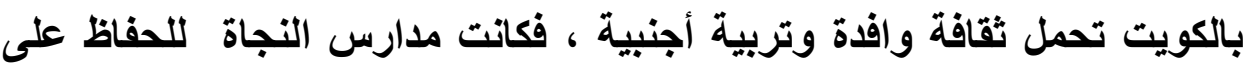

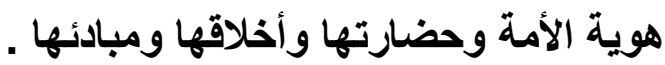

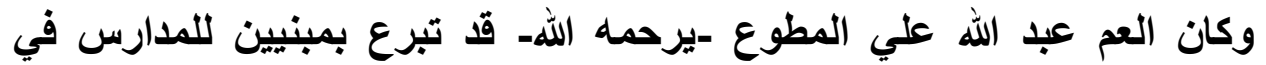

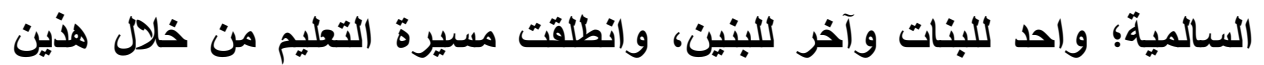

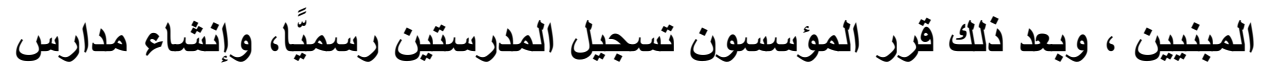
نظامية كاملة الأركان؛ حيث ذهب وفد منهم إلى الأمير الراحل الثيخ جابر الأحمد

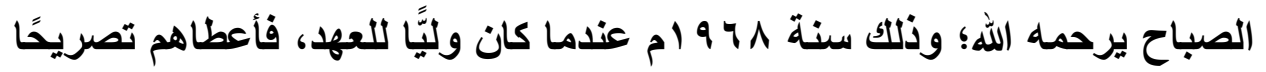
بمدرستين واحدة للبنين ورخصتها باسم مشاري إبداح الخشرم، والأخرى للبنات

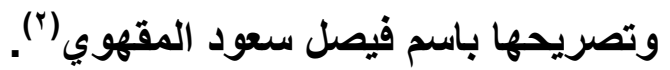

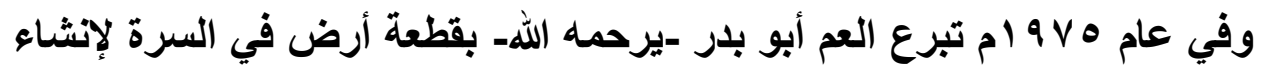

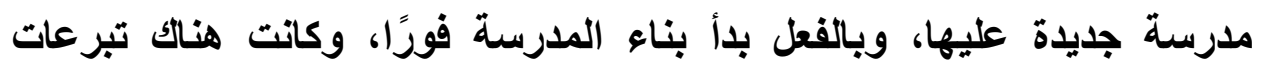

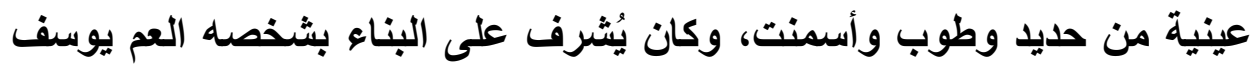
الحجي.

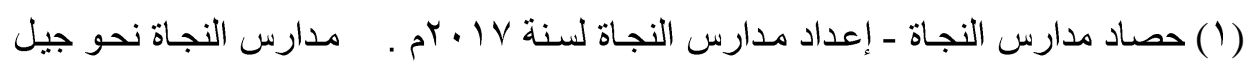

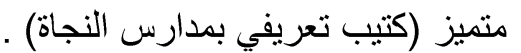

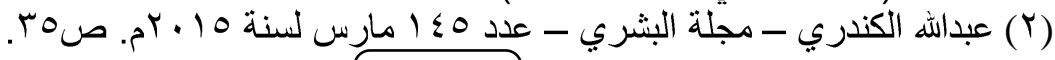
1.7 


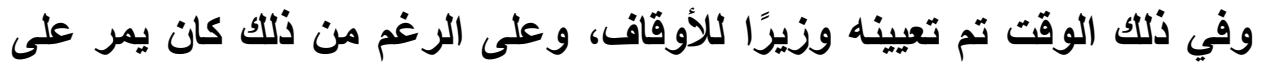

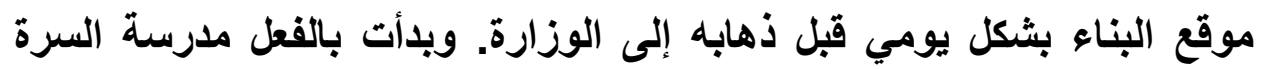

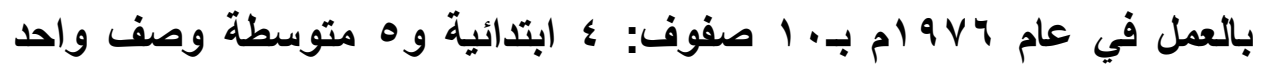
ثانوي ، وتثكَّل أول مجلس إدارة رسمي للمدارس من المؤسسين الكويتيين وهم:( أحمد بزيع الياسين - يوسف جاسم الحجي -جاسم الخرافي - فيصل سعود المقهوي - مشاري إبلاح الخثرم ـعبد الله علي المطوع- عبد اللطيف الشايع ـعلي الخضيري) (') وبذلك وضعت مدراس النجاة اللبنة الأولي للمدارس الأهلية بالكويت ، بثقافتها الإسلامية ومنهجها الرباني , ونشر ها للإسلام وترسيخ مفاهيمه وقيمه وأخلاقه

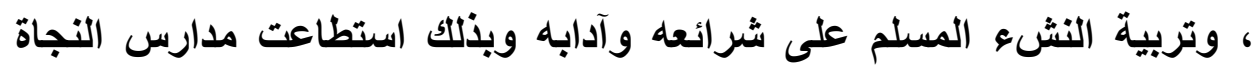
وأخواتها من الوقوف في وجه المدارس التبشيرية والتنصيرية التي تنشر الإحاد والنصرانية وتدعو للانحلال من الأخلاق الإسلامية ، وترسية وفئ ولة للتبعية

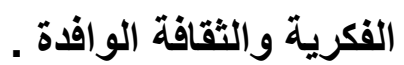
ما يتعلمه هؤلاء التلاميذ في المدارس من أكاذيب وأضاليل وتثثويهات متعمدة

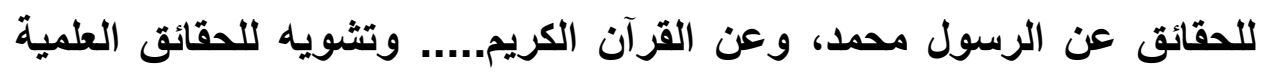

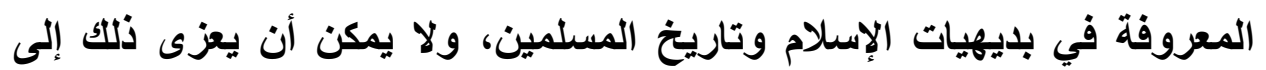
مجرد الجهل، بل إلى مبلغ الحقد الأي تحمله، والكيد الذي تكيده هذاته المؤسسات

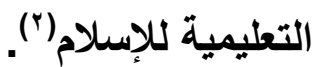

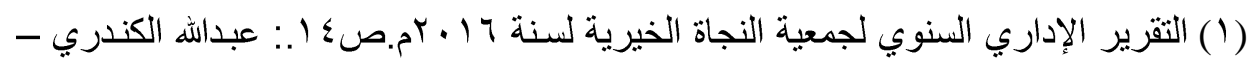

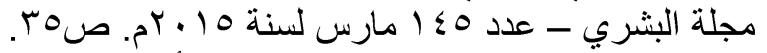

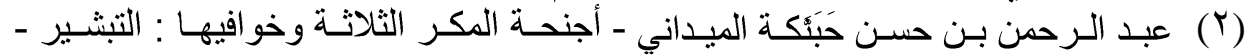

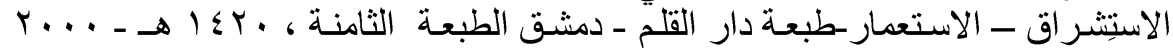

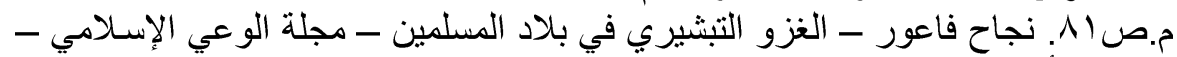

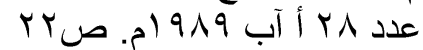


مدارس النجاة الخاصة بالكويت ودورها في تصحيح الخطاب الإسلامي

المبـهذ الثانـي: مدراسر النجاة (رؤيتها -أهدافها - رسالتها ).

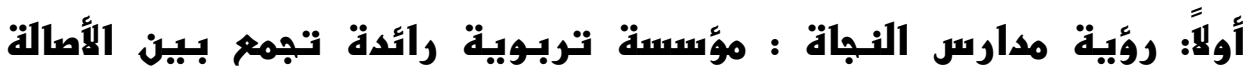

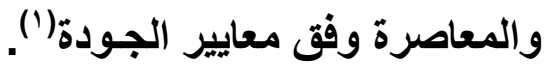

وبهذه الروئية حددت مدارس النجاة طريقة عملها وأدائها ومنهجها وائودها ، وأن المصادر الإسلامية والعربية هي أساس التربية ومورد التعليم ، بالطرق الحديثة والوسائل والأدوات المعاصر ، بالتطوير المستمر في الأداء والأفراد والوسائل بالئل

والأسـاليب(انو (r)

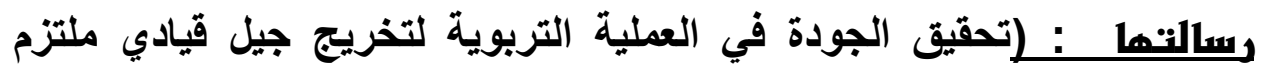
موهوب من خلال إدارة عصرية متميزة تعمل على التحسين المستمر بكفاعات

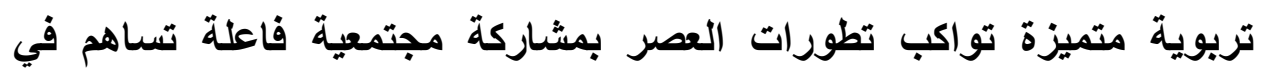

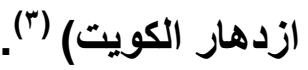

إن هذه الرسالة تتحقق بالوظائف الدراسية القائمة على المنهج العلمي السديد ،

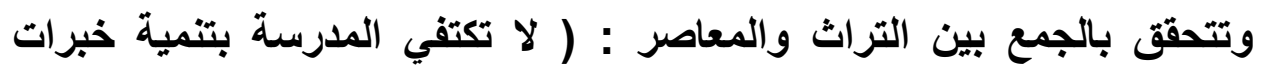

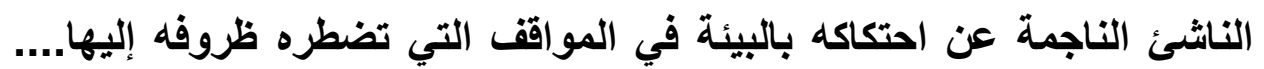

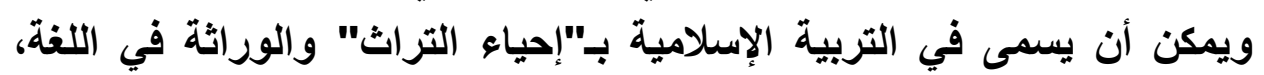
وانتقال الثروة من السلف إلى الخلف، ويطلق على ذلتك الثروات الفكرية،

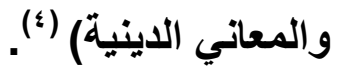
تلك الرسالة في حقيقتها تخدم كل الناس ، وأقترح ان تكون الصياغة (( تواكب

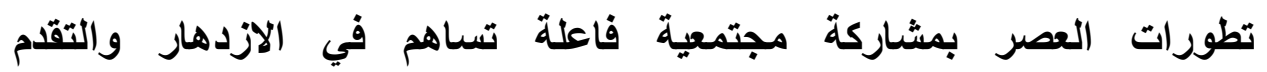
لأوطان()(ن).

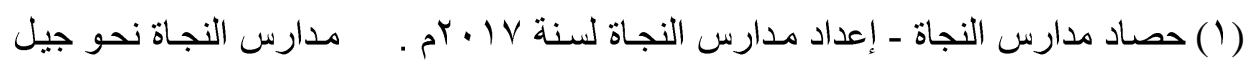

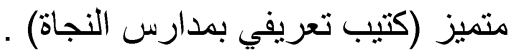

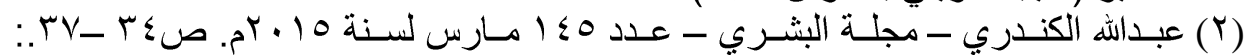
مدارس النجاة نحو جيل متميز (كتيب تعريفي بمدارس النجاة) .

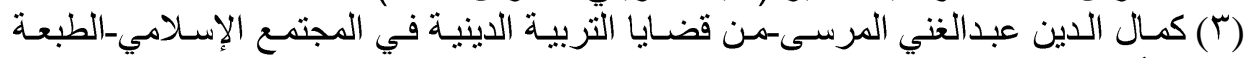

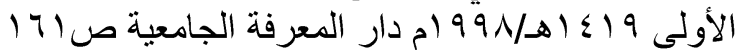

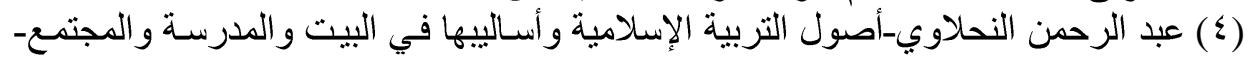

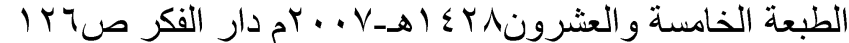

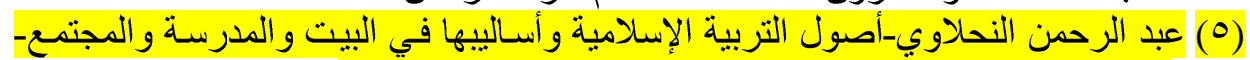

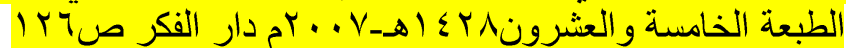

$1 \cdot \Lambda$ 


\section{أنهافهافا}

1- ت تنميـة القيـادة التربويـة الصاعدة المتميزة .

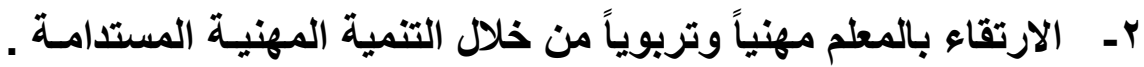

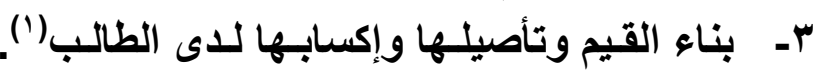
ــ اكتشاف ورعاية الموهوبين ومراعاة حاجاتهم التي تشهم في تحقيق نواتج التعلم.

0ـ تحقيق الرضا الوظيفي لجميع العاملين لتحقيق أهداف المؤسسـة .

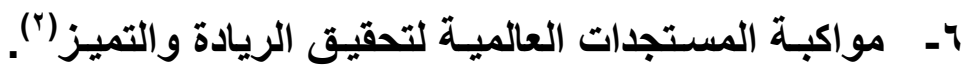
إن تعيين الههف له أهمية تجعله ضروريا لكل ضروب السلوك الواعي، فكيف

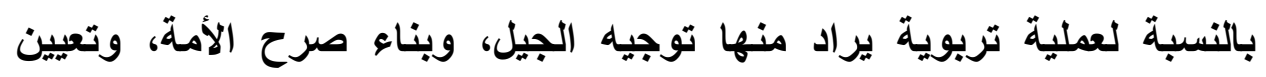

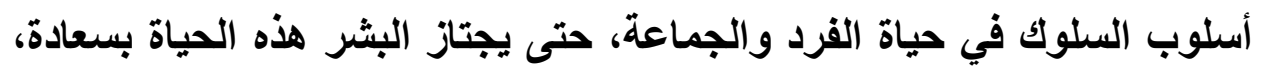

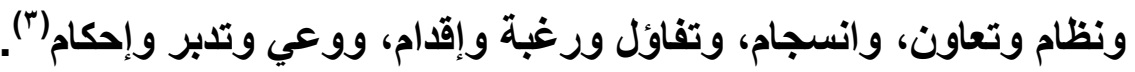

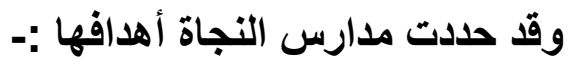
1- الأهداف الخاصة بالمعلم من اختياره والحفاظ عليه وصيانته من المهانة

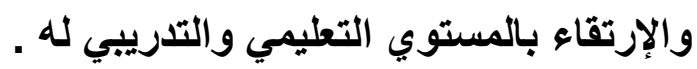

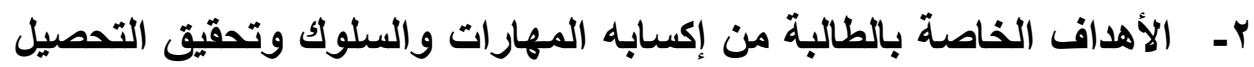

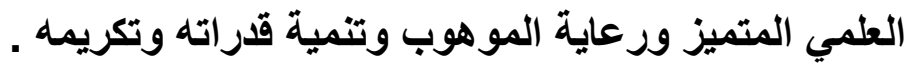
r- الأهداف الإدارية والريادة فيها ، والعدل بين الموظفين ، ومواكبة كل

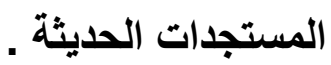

ثانياً: قيم مدارس النجاة :التمييز...النماء.. الأصالة .. المعاصرة .. الجودة... (؛).

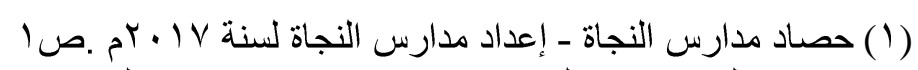

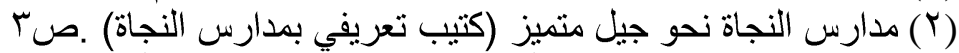

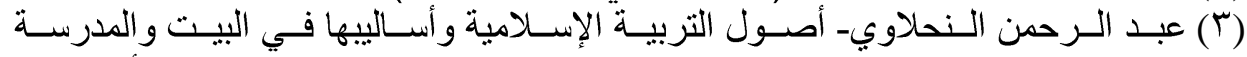

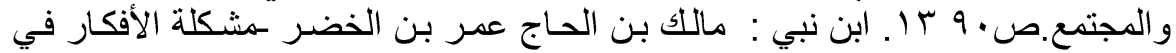

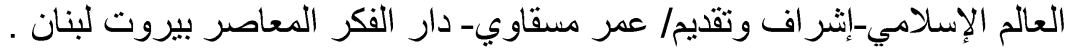

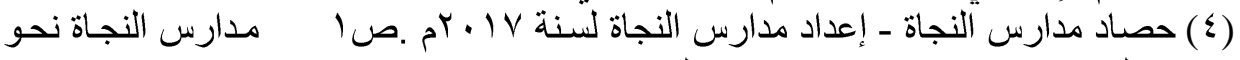

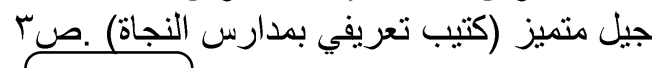
1.9 
هذه القيم التي تتتهجها مدارس التجاة إسلامية المصدر وعربية الهوية ،

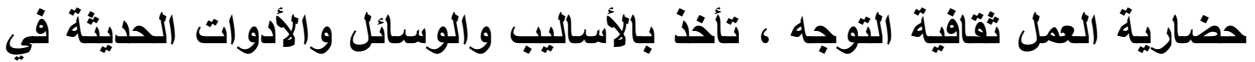

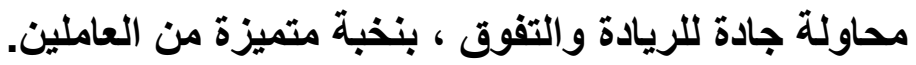

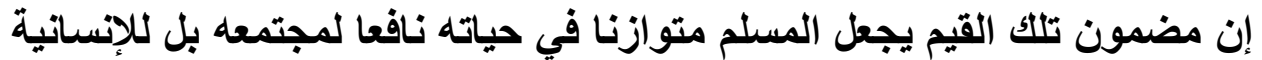
جمعاء، وما يحيط بها من البيئة. وتجعله عنصر إسعاد لنفسه ولغيره ... العضو

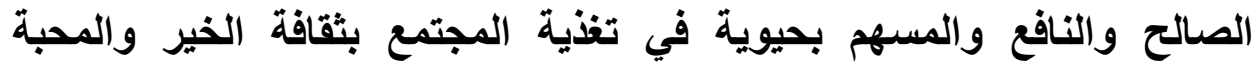

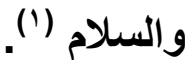
وهذه القيم أخلاق إسلامية خالصة ، ودافع إيمانية نقية ، وقصص قرآنية

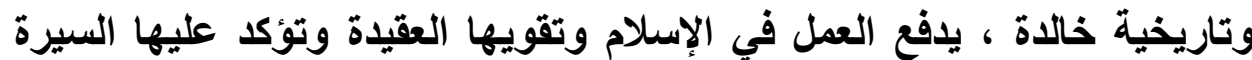
النبوية العطرة ما الإسلام في حقيقته إلا مجموعة أخلاق قوية ترمي إلى شد المجموع من كل

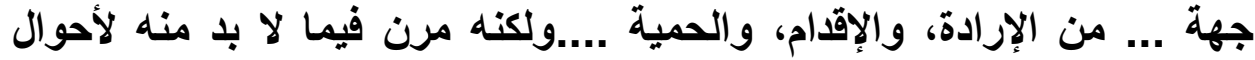

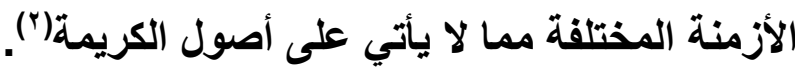
وتؤكد الإدارة العامة لمدارس النجاة : لايها مجموعة من المشاريع التربوية لإية والتعليمية من أبرزها مشروع القيم من خلاله يتم تنظيم عدداً من الأنشطة يتم

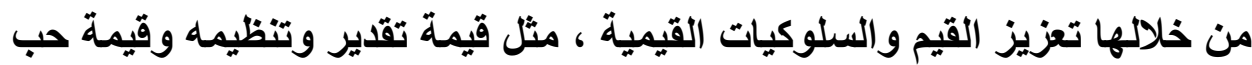
الوطن بالإضافة إلى إنشاء مشروع أكاديمية للقرآن الكريم ، ومشروع التعليم

الإلكتروني

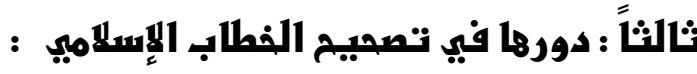
تقوم مدارس النجاة على إعداد جيل مسلم من النشع الصغير مثقف ومتعلم ،

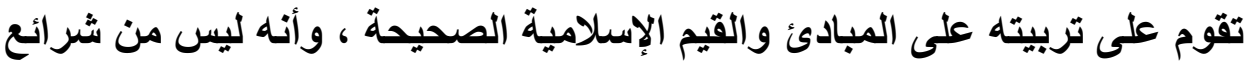

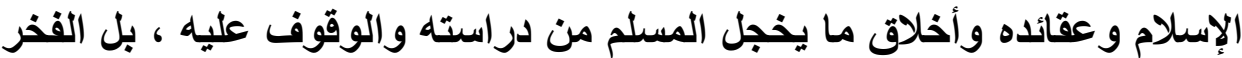
كله لما ورد في دين الله عز وجل ، ورفع الجهل والتعليم الصحيح هو أهم ركن

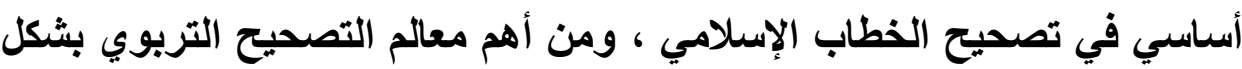

(1) عبد السـلام الهـراس الإسـلام - ديـن الوسطية و الفضـائل و القبم الخالـدة- وزارة الأوقـاف

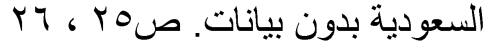

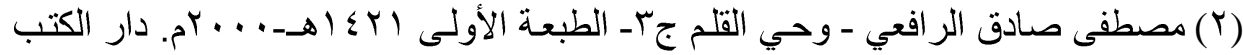


مجلة كلية الآداب، جامعة سوهاج، العدد الثاني والخمسون، الجزء الثاني، يوليو 9 1 ـ Yم

العام ، والتربية الإسلامية بشكل خاص التي تتتهجها مدارس التجاة في مادتها العلمية ، وطريقتها التربوية ، ومنها مادة التربية الإسلامية :

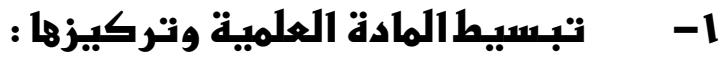

تبسيط المادة وتسهيلها حتى يستطيع الطالب الاستيعاب والإدراك ، والكة والتحصيل بشكل سريع ومثمر ، ليشمل أكبر قر من القرآن والسنة والعلوم الإسلامية

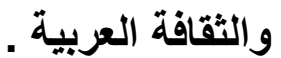

والتبسيط يجب أن يلتقي مع التلخيص، وهو اختصار هذه المظاهر، والعلوم الواسعة المترامية الأطراف إلى مبادئ يسهل استيعابها، وتثمل أكبر قدر ممكن من التطبيقات، ومما يحتاجه الناثئ في حياته ومجتمعه، كما يستعمل لغة أمته في التفاهم مع إخوانه في العقيدة، وفي مناجاة ربه، والتعبير(').

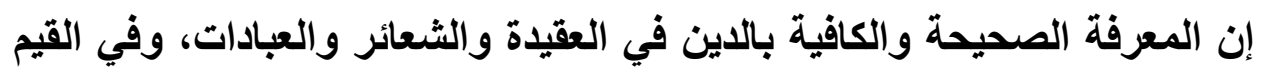

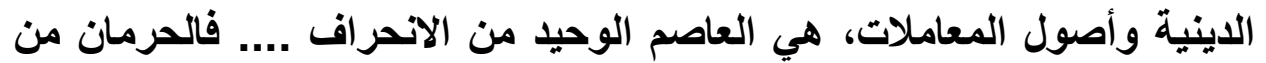

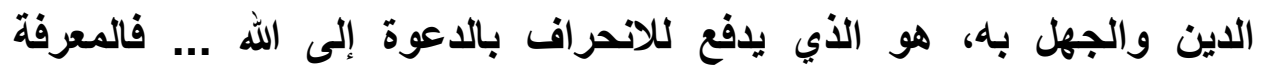
الصحيحة بأحكام الاين، هي أول عناصر التصحيح في هذا في هذا الانحراف(؟).

\section{l. تطهير المادة العلمبة وتصفيتها :}

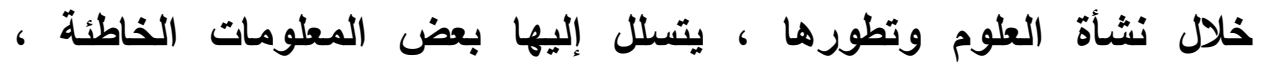

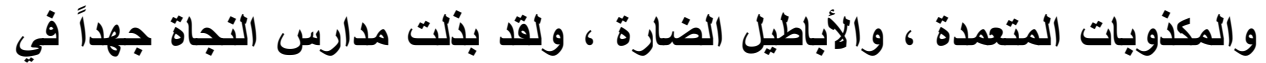

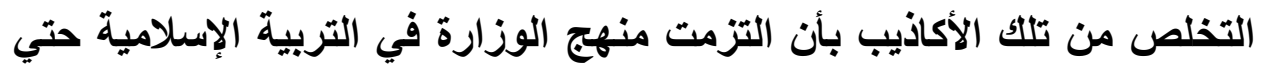
يكون خطاباً إسلاميا صحيحاً خالياً من الثوائب التبان . مرت العلوم أو العقيدة على عقول أجيال متتابعة من الناس والمجتمعات، فلا تبقى على حالها، بل تتحمل كثيرا من الثوائب، والعواطف الكاذبة، والمبالغاته هنول الخاطئة...... والمدرسة عندما تقدم العقيدة والعلم إلى الناشئين، تعمد إلى تصفية ولية

(1) عبد الرحمن النحلاوي- أصول التربية الإسلامية وأساليبها في البيت و المدرسـة والمجتمـع.

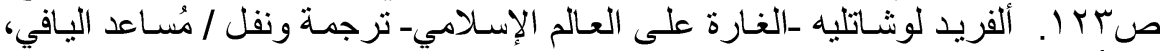

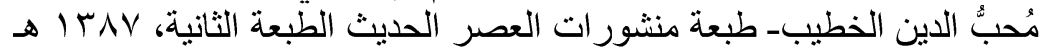

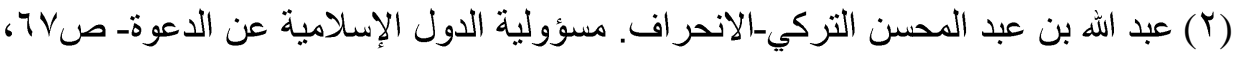


الحقائق، وتثقيتها من كل الثوائب والأخطاء، والمبالغات والأكاذيب، لتبقى

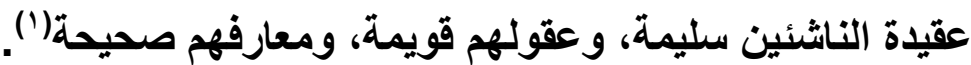
لقد كاتت التربية الأولي عند المسلمين بقيادة نبيها الأمين-صلى الله عليه وسلم فولماريه ـ في تصحيح العقائد والثرائع والأخلاق ، جملة طيبة من العطاء و والسمو عن الأن

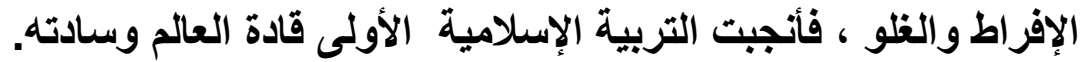
إن التربية الإيمانية للرعيل الأول من جيل الصحابة رضوان الإنهانه الله عليه ، جعلتهم

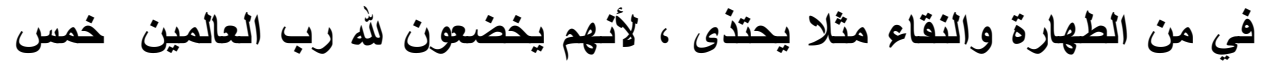

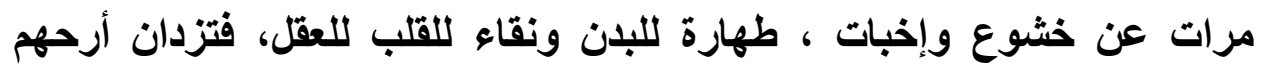

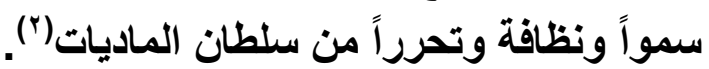
هذا وتبذل مدارس النجاة في منهجها وعلومها وتربيتها الجمع بين القول والعمل ونل مئل

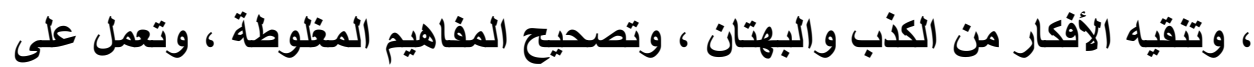

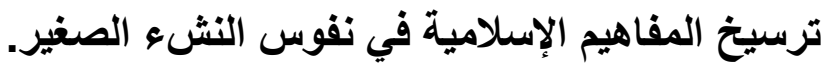

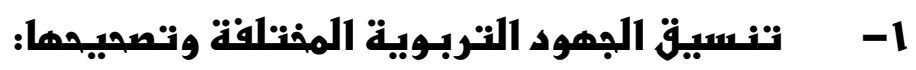
يشترك في التربية عوامل وجهات متعددة كالبيت والمجتمع ووسائل الإعلام

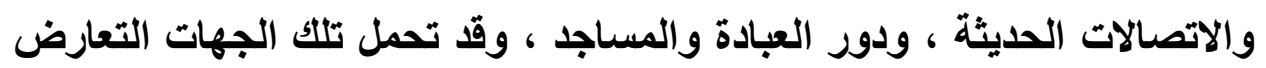

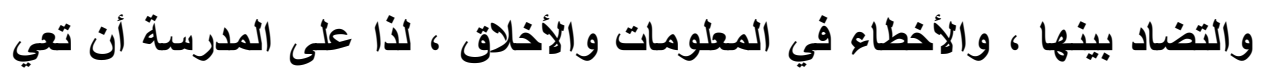

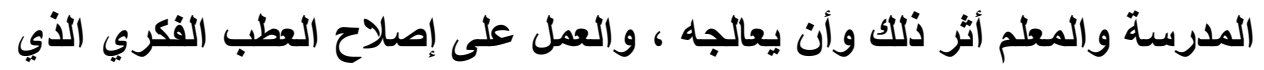

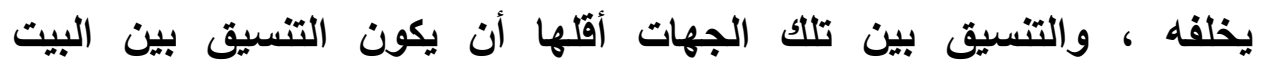

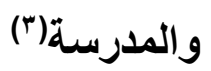

إن مبالغات بعض الصحف والمحطات الإذاعية والإعلامية ، وما تحمله من

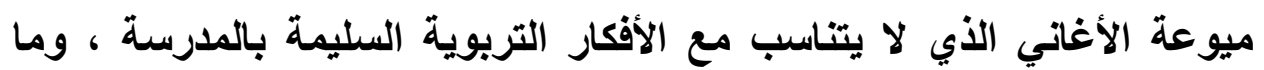
تقدمه من معلومات صحيحة ، لذا وجب على المدرسة أن تنسق جهودها بالتعاون المباشر مع المؤسسات والأسر لتفادي أضرار تلكك المؤثرات التربوية ،

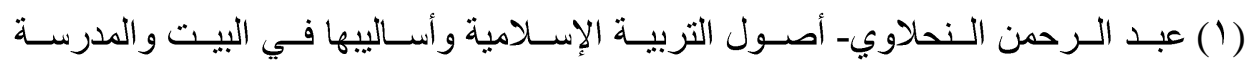

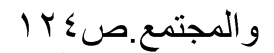

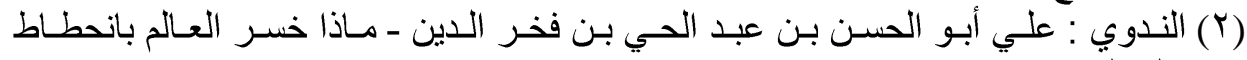

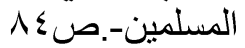
(r) عبد الرحمن النحلاوي- أصول التربية الإسلامية وأسـاليبها في البيت و المدرسـة والمجتمع 
ونثر الآراء السليمة لهؤلاء الطلاب في منازلهم وبين أهلهم ، وبيان أسسها

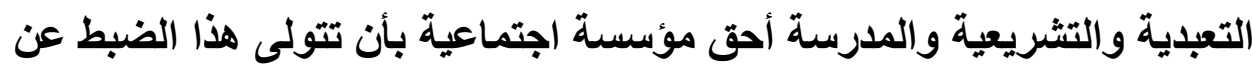

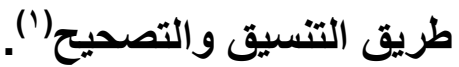
تبذل مدارس النجاة جها كبير في تربية النشع على أسس سليمة خلال الآتي :

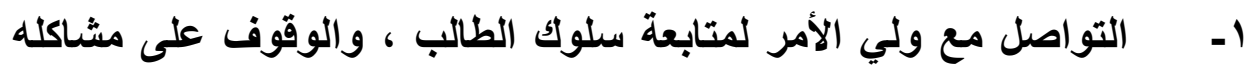
الأخلاقية والصحية للتعامل معاه . r- التقارب مع الطلب لاستخراج مواهبه والتظلب على المؤثرات التربوية

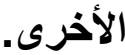

r- إقامة الندوات والدورات التثقيفيـة للطالب والمطلم ، التي تحمل صحيح

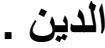

عـ - الرعاية الاجتماعية والنفسية والسلوكية ، من خلال الأخصائيين والإدارة

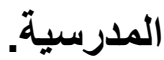

\section{رابعاً التربية وأثرها في الفطاب الإسلامير نهو النتمية والتصهيح :}

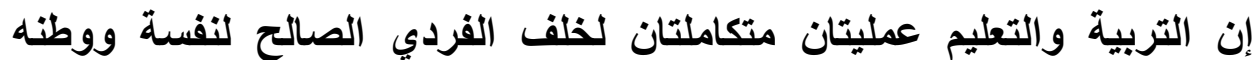
ودينيه : (إذا كان التعلم يخاطب العقل في الإنسان فإن التربية تخاطب الروح

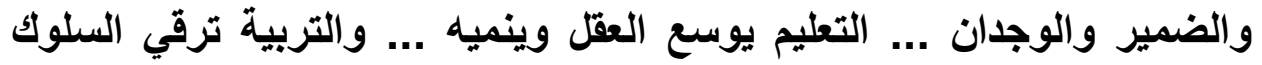
وتزكيه... ومن ثم كانت التربية في المنظور الإسلامي إنما تهائ إلى تنشئئة

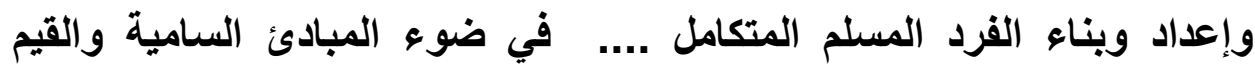

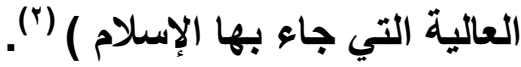

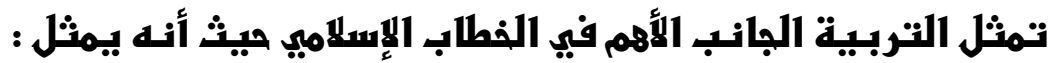
1. التربية هي الجانب العملي السلوكي للتعليم والدعوة والخطاب الإسلامي فهي تمثل نصف الدعوة الأهم . r. تمثل تربية النش وتعليمهم مرحلة بناء الأمة كلها ، فهم أصحاب المهن و التخصصات التي تسير حياة الأمة في المستقبل القريب .

(1) محمد منير مرسيـ التربية الإسـلامية أصولها وتطور هـا في البلاد العربيةــ طبعة عالم

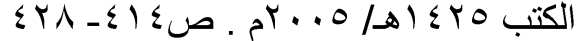

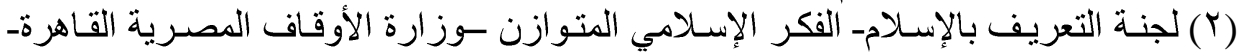

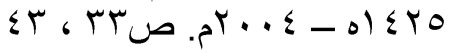


r. إن التربية هي تقويم السلوك والأفكار ، وتصحيح العقائد والمذاهب ، ورد التيارات الفكرية الهدامة والثقافة الغريبة الوافئ الثدة.

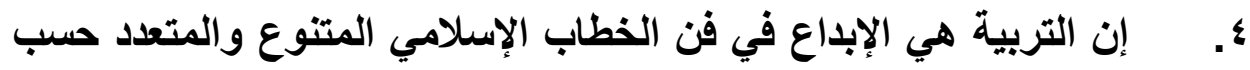
المراحل العمرية لفئات الطلاب المختلفة.

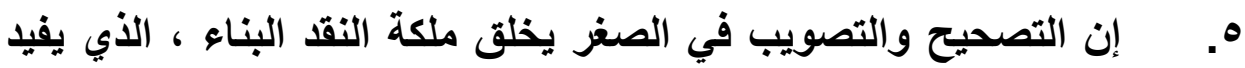

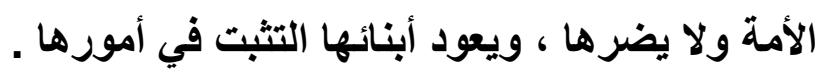

الفاتمة

\section{أهم النتنائج}

أ. إن مدارس التجاة تقوم على نشر الثقافة الإسلامية في مدارسها وتربية

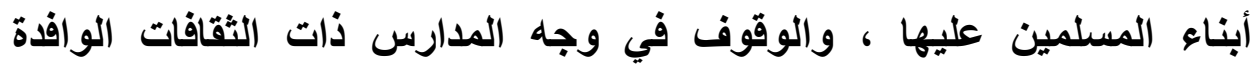
المناهضة للإسلام. r. تعمل مدارس التجاة على تقديم الدورات التدريبية والتعليمية في العلوم

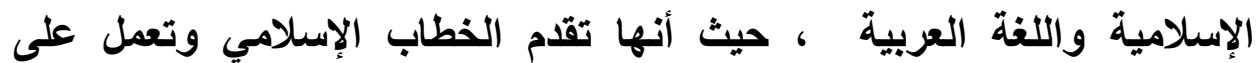
تصحيحه والارتقاء به. r. تقف مدارس التجاة بجميع مراحلها، في وجه التبشير والاستشراق

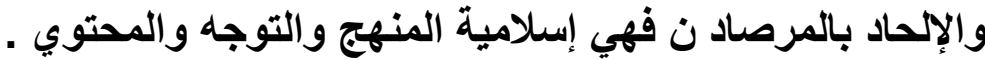

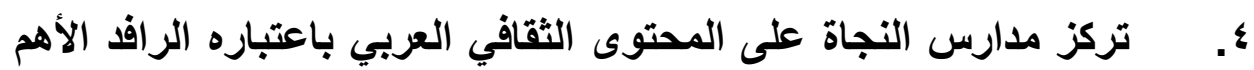
للخطاب الإسلامي ، الذي يمكنتا من الاطلاع على مصادر الخطاب الإسلامي

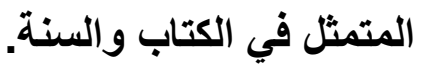

\section{1التوصبات}

ا- - إقامة المدراس الإسلامية باللغات الأجنبية لسد الحاجة إلى التعلم في

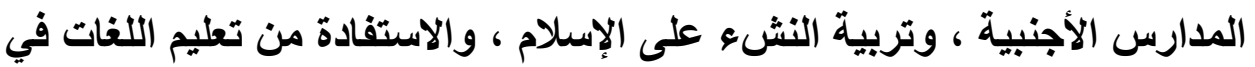
الدعوة الإسلامية وإثراء الخطاب الإسلامي وتصحيح المفاهيم المغلوطة الإنه

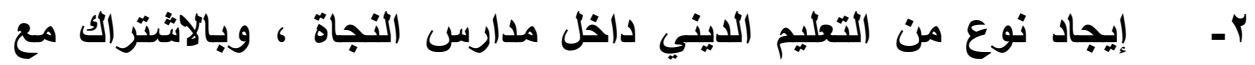

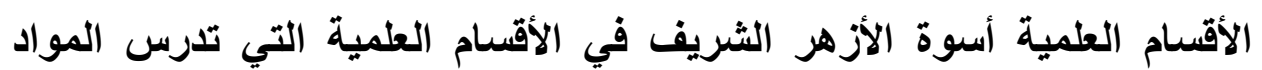
الثقافية والاينية . الأينام 
مجلة كلية الآداب، جامعة سوهاج، العدد الثاني والخمسون، الجزء الثاني، يوليو 9 1 ـ Yم

r- الاستفادة من خبرات المدارس والجمعات الإسلامية كالجامعات الأمريكية

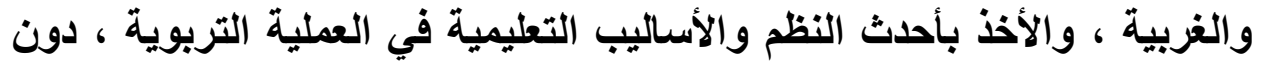
التخلي عن المنهج الإسلامي في المحتوى الأكاديمي.

\section{فهر سر المراجم والمصادر}

ا. . ابن نبي : مالك بن الحاج عمر بن الخضر -مشكلة الأفكار في العالم الإسلامي-إشراف وتقديم/ عمر مسقاوي- دار الفكر المعاصر بيروت لبنان.

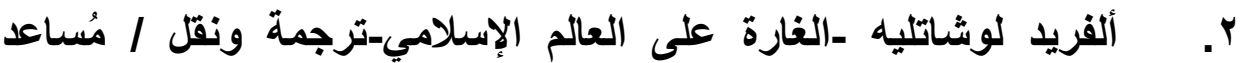
اليافي، مُحبُّ الدين الخطيب-طبعة منشورات العصر الحديث الطبعة الثانية A IMN

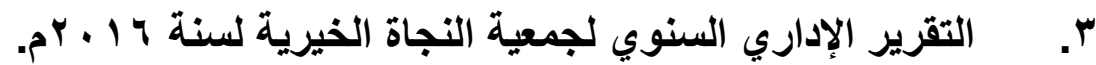
ع. الندوي : علي أبو الحسن بن عبد الحي بن فخر الدين - ماذا خسر العالم

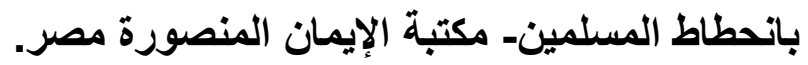

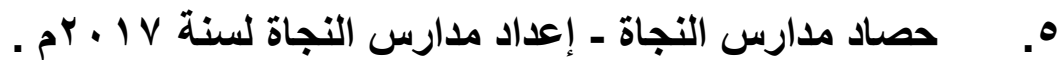

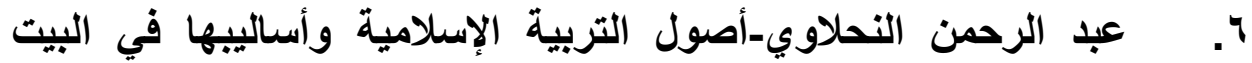

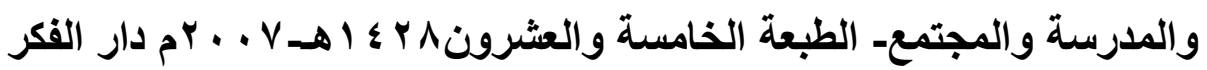

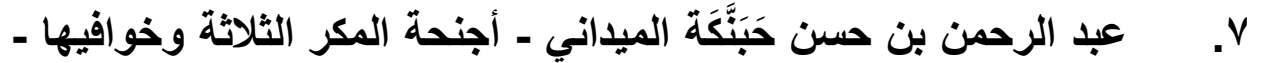

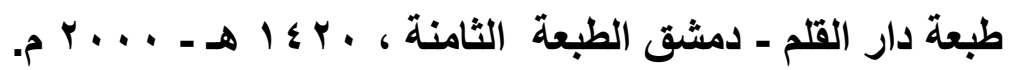
^. عبد السلام الهراس الإسلام - دين الوسطية والفضائل والقيم الخالدة. وزارة الأوقاف السعودية بدون بيانات. 9. عبد الله بن عبد المحسن التركي-الاتحراف. مسؤولية الدول بلاند الإسلامية عن الاعوة- بلون بيانات.

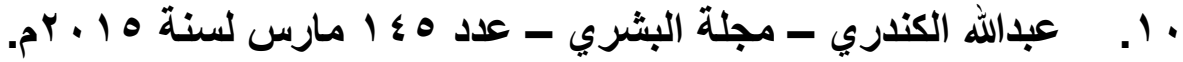

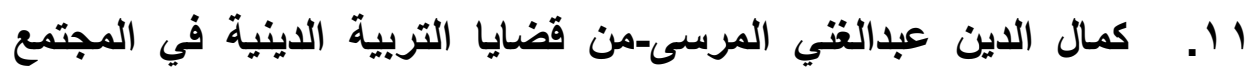

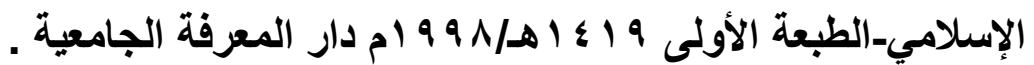

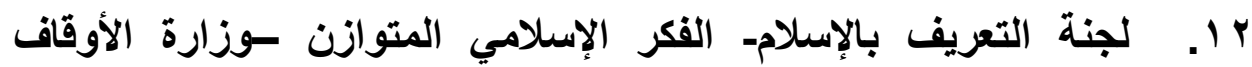

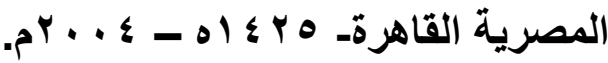


مدارس النجاة الخاصة بالكويت ودورها في تصحيح الخطاب الإسلامي

r ا. . محمد منير مرسي- التربية الإسلامية أصولها وتظورها في البلاد

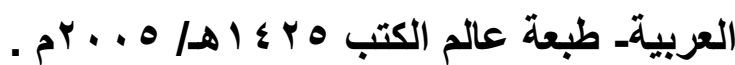

ع 1. مدارس النجاة نحو جيل متميز (كتيب تعريفي بمدارس النجاة) .

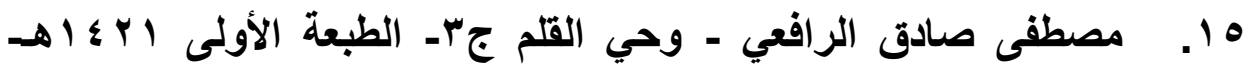

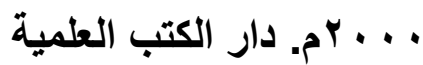

17. نجاح فاعور - الغزو التبشيري في بلاد المسلمين - مجلة الوعي

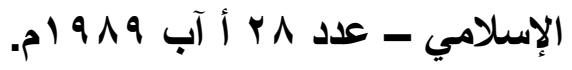

